\title{
Interactions between microstructure and fatigue crack growth in $\alpha \beta$ titanium alloy
}

\author{
Vincent Renon ${ }^{1,2}$, Gilbert Henaff ${ }^{2}$, Céline Larignon ${ }^{1}$, Simon Perusin ${ }^{1}$, Patrick Villechaise ${ }^{2}$.
}

${ }^{1}$ IRT Saint Exupery, B612, 3 rue Tarfaya, CS 34436, 31405 Toulouse Cedex 4, France; vincent.renon@ensma.fr (V.R.); simon.perusin@irt-saintexupery.com (S.P.)

2 INSTITUT Pprime UPR 3346 CNRS ENSMA Université de Poitiers, ISAE-ENSMA, 1 Avenue Clément Ader, 86961 Futuroscope Chasseneuil Cedex, France; patrick.villechaise@ensma.fr (P.V)

* Correspondence: gilbert.henaff@isae-ensma.fr (G.H.); celine.larignon@irt-saintexupery.com (C.L.); Tel.:+33-549498233 (G.H.); +33-561006767 (C.L.)

$\underline{\text { Abstract }}$

In a context of optimization of the crack propagation resistance properties in $\alpha \beta$ titanium alloys, this work aim to explore interactions between microstructure and deformation at crack tip in lamellar titanium alloy, especially regarding to the differences between the two propagation regimes observed in these alloys. Analysis of crack path in these two propagation regimes will be performed with EBSD measurements at mid-thickness to characterize the crystallography contribution during propagation. This analysis indicates a strong propensity to cracking along crystallographic planes in the first propagation regime, followed by a reduction of this trend after the transition between the two regimes.

\section{Introduction}

This study deals with the influence of microstructure on the fatigue crack growth resistance of Ti-6Al-4V ELI titanium alloy. This alloy may compete with the conventional Ti-6Al-4V alloy to manufacture high performance aircraft component provided that their fatigue crack growth properties can be improved by proper heat treatments without substantial degradation of other properties.

Crack growth tests have been performed on CT specimens in ambient air, with a load ratio of 0.1 , and for $\Delta \mathrm{K}$ values ranging from 15 to $40 \mathrm{MPa} / \mathrm{m}$ [1]. The results outline a transition between two propagation regimes, at a value of the variation of stress intensity factor $\Delta \mathrm{K}=25 \mathrm{MPa} \vee \mathrm{m}$, the first regime before transition presenting reduced crack growth rate (Figure 1). Fractographs and crack path observations have been performed to characterize each propagation regime. Complementary analysis with 3D measurements of crack surface allows to confront the results with the hypothesis present in the literature dealing with a transition from a crystallographic/microstructure-sensitive (stake I like) propagation to a regime characterized with a lower influence of microstructure (stage II) [2-4].

(C) The Authors, published by EDP Sciences. This is an open access article distributed under the terms of the Creative Commons Attribution License 4.0 (http://creativecommons.org/licenses/by/4.0/). 


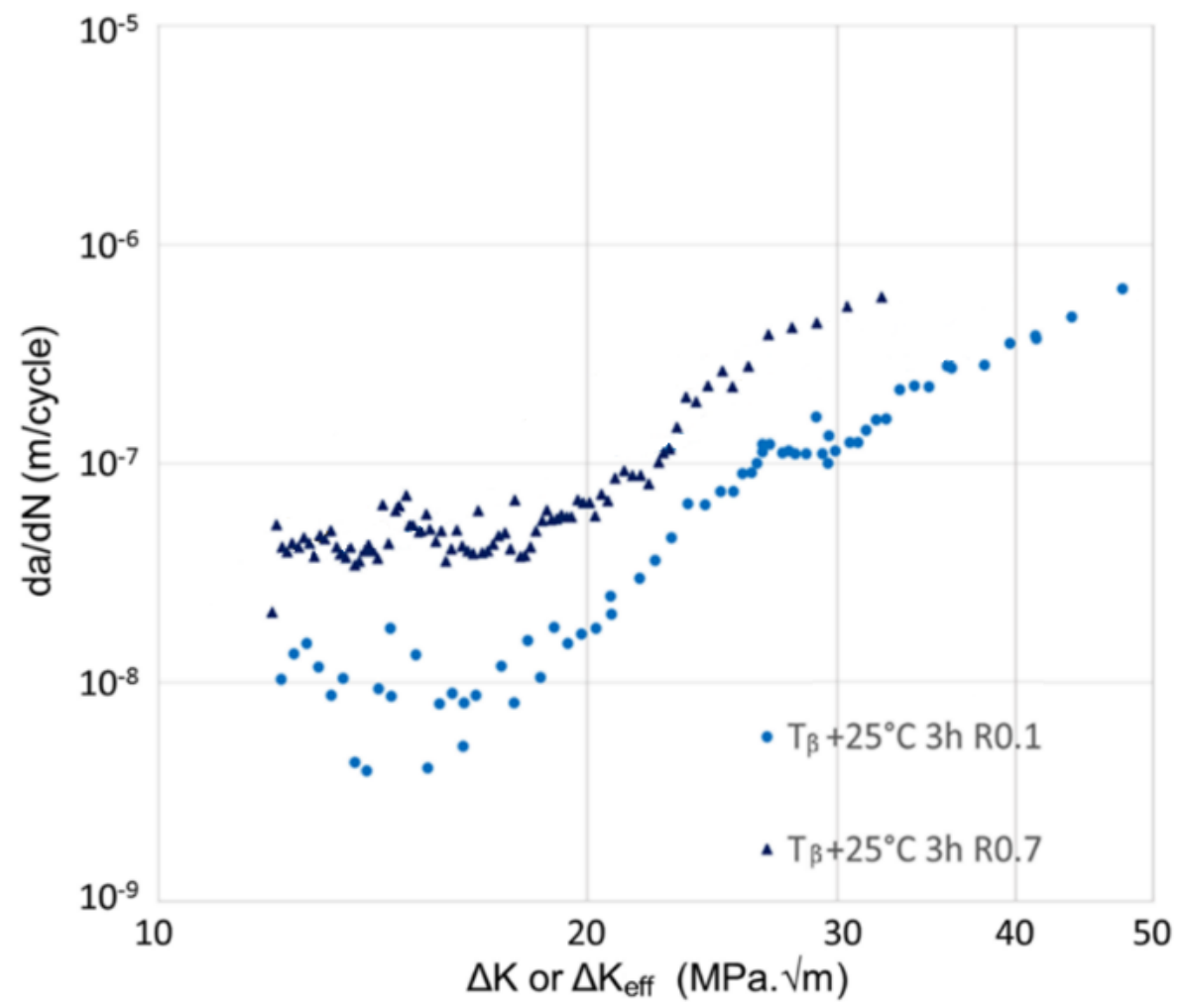

Figure 1:Crack propagation test at $R=0.1$ and $R=0.7$ for lamellar microstructure obtained with annealing temperature $T \beta+25^{\circ} \mathrm{C}$ for $3 \mathrm{~h}$ followed by ageing at $730^{\circ} \mathrm{C}$ for $1 \mathrm{~h}$

The aim of this work is then to improve the understanding of the differences in deformation and propagation mechanisms at the crack tip between the two outlined propagation regimes. In continuity of the previous study, the presented work will focus on the confirmation of the more crystallographic aspect of the propagation in the first propagation regime.

\section{Material and experiments}

Material

All the samples tested were machined from a 1 meter long, and $180 \mathrm{~mm}$ diameter billet provided by TIMET and forged in the $\alpha-\beta$ domain. The measured chemical composition (in weight \%) of this billet is given in Table 1. The $\beta$ transus temperature is evaluated, according to chemical composition, at $980^{\circ} \mathrm{C}$.

\begin{tabular}{|c|c|c|c|c|c|c|c|}
\hline Table 1 : Measured chemical composition of the Ti-6Al-4V ELI alloy under study. \\
\hline Aluminum & Vanadium & Carbon & Iron & Oxygen & Nitrogen & Hydrogen & Titanium \\
\hline 6.2 & 4.0 & 0.02 & 0.16 & 0.12 & 0.002 & $<0.003$ & Balance \\
\hline
\end{tabular}


The resulting microstructure is a fully lamellar microstructure with an average prior $\beta$ grain size of $1686 \mu \mathrm{m}$, an average lamellae colonies thickness of $425 \mu \mathrm{m}$ and an average lamellae thickness of $1.46 \mu \mathrm{m}$. This microstructure is presented on Figure 2 using polarized optical microscopy and SEM techniques.

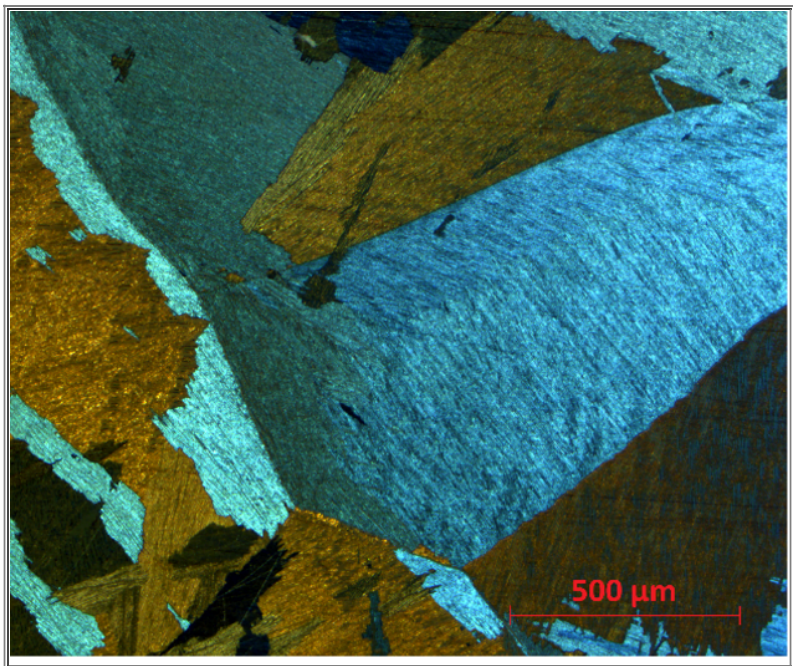

(a)

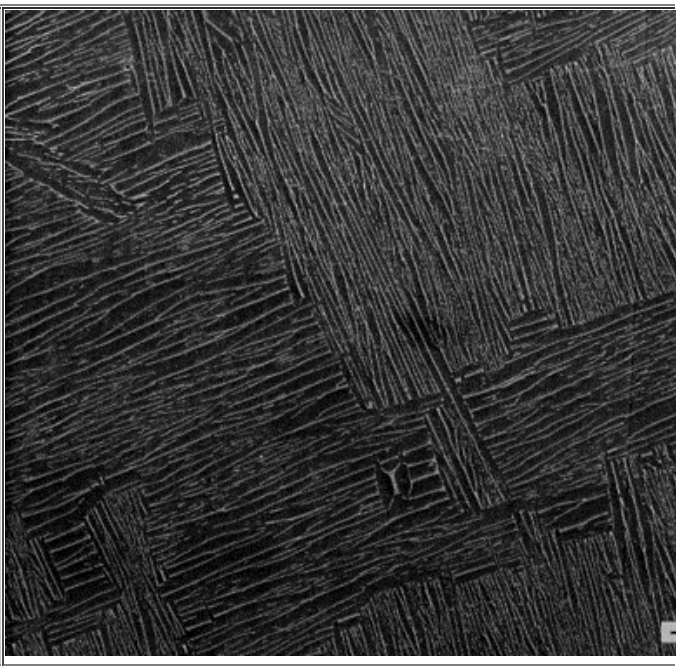

(b)

Figure 2: Lamellar microstructure obtained with annealing temperature $\mathrm{T} \beta+25^{\circ} \mathrm{C}$ for $3 \mathrm{~h}$ followed by ageing at $730^{\circ} \mathrm{C}$ for $1 \mathrm{~h}$, viewed with polarized optical microscopy (a) and SEM (b).

Three CT samples have been machined for crack propagation tests. Three different crack propagation tests at constant stress intensity range have been performed and interrupted before final failure. This three test were performed at a frequency of $20 \mathrm{~Hz}$, in air at ambient temperature. The first was carried out at a load ratio $R=0.1$ and a constant variation of stress intensity range $\Delta K=20$ $\mathrm{MPa} \sqrt{\mathrm{m}}$. Therefore, the propagation for this test stayed in the first propagation regime. The second test was performed with the same load ratio, but with a stress intensity range $\Delta \mathrm{K}=40 \mathrm{MPa} / \mathrm{m}$, thus in the second propagation regime. Finally, a third test was carried out at a load ratio $R=0.7$ and a stress intensity range $\Delta K=20 \mathrm{MPa} / \mathrm{m}$.

These three crack propagation tests were interrupted after a crack advance $a=25 \mathrm{~mm}$. After mechanical testing, the samples were cut at mid-thickness in order to observe the crack path in the plane strain region, as shown on the Figure 3.

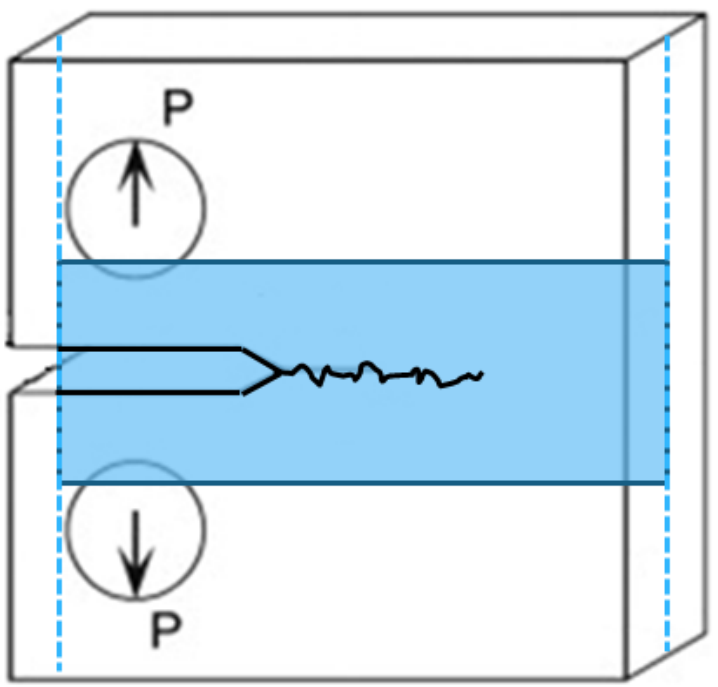


After cutting, the sample face was prepared for observation by polishing up to $\mathrm{SiC} 4000$ grade paper, before finish with an OP-S and $\mathrm{H} 2 \mathrm{O} 2$ (10\%) solution. The rear face of the sample was also polished, up to SiC 2000 paper, with a special care to keep the rear face parallel to the observed face, in view of the EBSD scan.

The EBSD analysis was performed on the prepared sample (dimensions $17.5 \mathrm{~mm} * 2.7 \mathrm{~mm}$ approximately) with a JEOL 6100 SEM, using a $4 \mu \mathrm{m}$ step, in order to scan all the sample surface in a reasonable time frame.

Results

The results of the three scans are presented on Figures 4 to 6 . With crystal orientations data obtained from EBSD, each segment of propagation can be referenced to a crystallographic plane. Furthermore, as result of the acquisition steps, very small propagation segment $(<15 \mu \mathrm{m})$ could not be clearly related to a crystallographic plane. Another implication of the size of the step is that an alternation of very small propagation segments according to different crystallographic planes could appear as non-crystallographic propagation. But, in regard to the average size of the propagation segments (approximately 150 $\mu \mathrm{m}$ ), this effect is considered as insignificant. The red and blue segments in the figures represent the traces along the crack path of basal and prismatic planes. In this analysis, only the main crack path is considered, therefore, all the secondary crack that does not connect with the main crack are not considered, as well as pre-cracking.

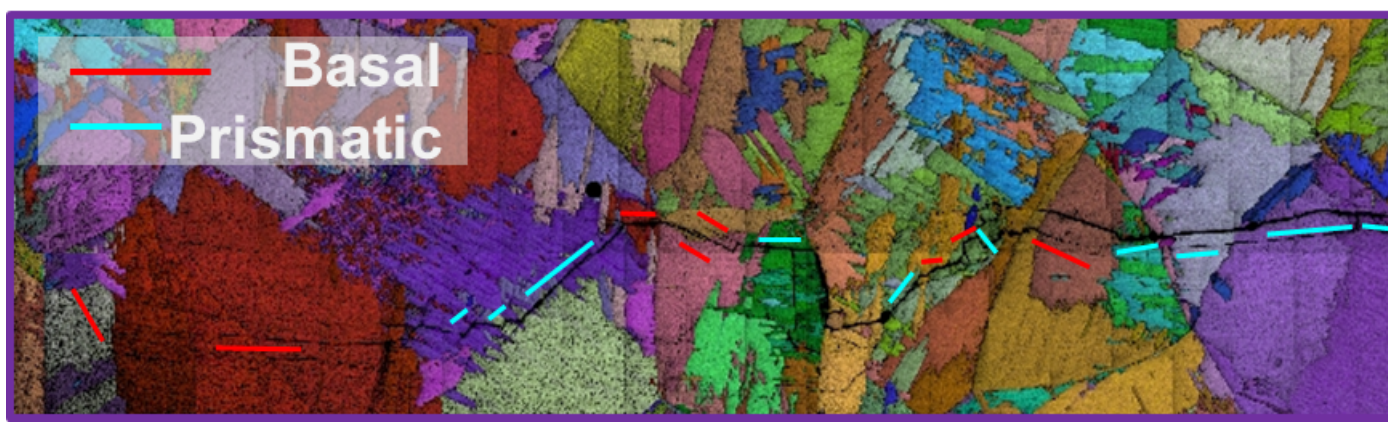

Figure 4: EBSD analysis of crack path for the $R=0.1 \triangle \mathrm{K}=20 \mathrm{MPa}$ m test.

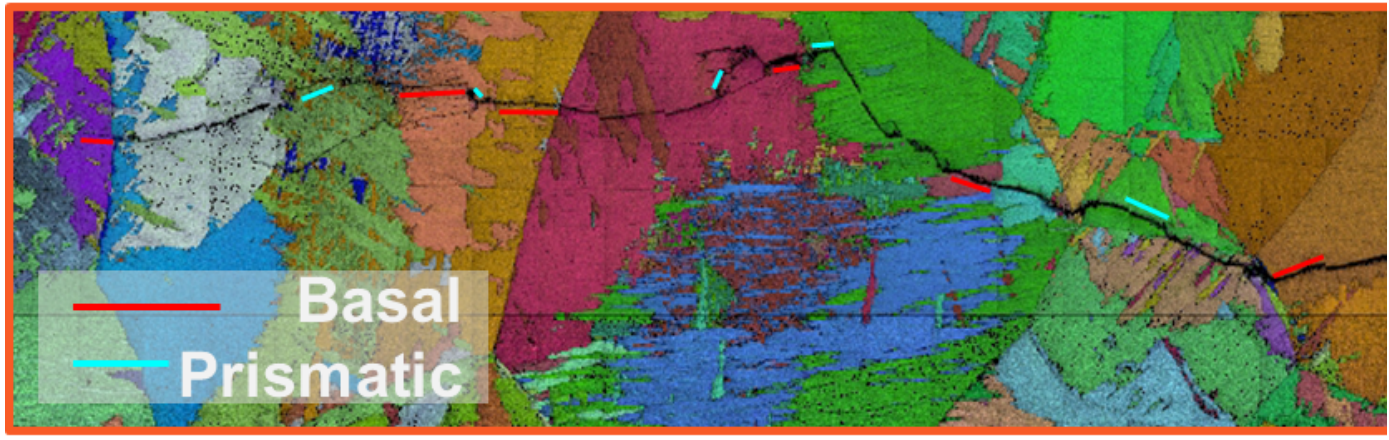

Figure 5 : $E B S D$ analysis of crack path for the $R=0.1 \triangle K=40 \mathrm{MPa} \sqrt{ } \mathrm{m}$ test. 


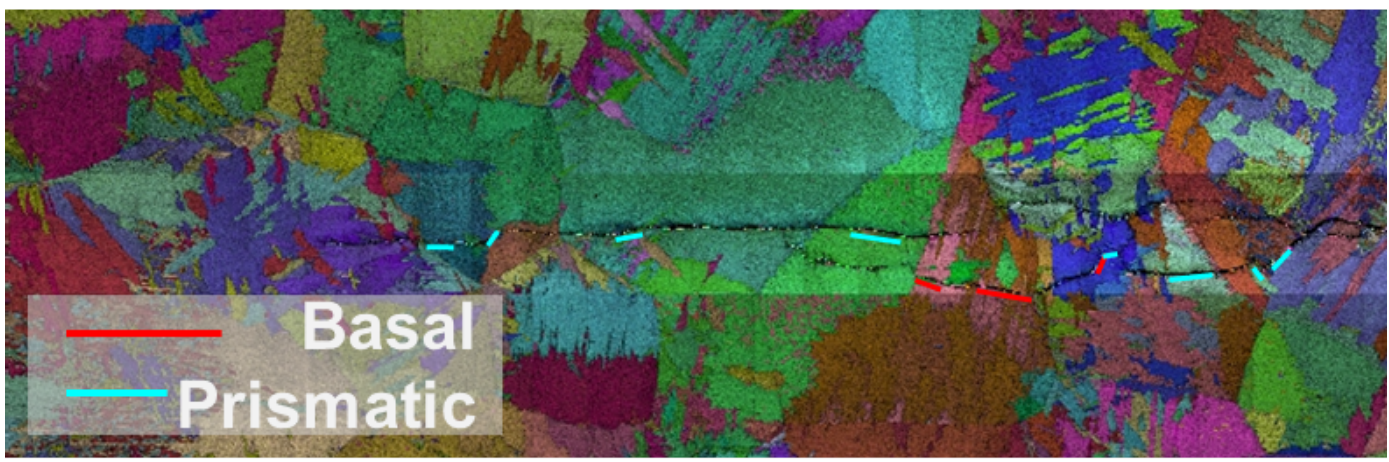

Figure 6: $E B S D$ analysis of crack path for the $R=0.7 \Delta K=20 \mathrm{MPa}$ /m test.

It is visible by comparing Figure 5 to Figure 4 and Figure 6 , that a smaller proportion of segments can be related to a crystallographic plane at high values of stress intensity factor variation, above the transition. The comparison of Figure 4 to Figure 6 indicates a similar propensity to crystallographic propagation before the transition at $R=0.1$ and $R=0.7$.

From these acquisitions, each propagation segment is measured and the proportion of propagation segment following a crystallographic trace is calculated. The calculated values are presented on table 2 .

Table 2 : Proportion of crystallographic propagation along the crack path.
\begin{tabular}{|c|c|c|c|}
\hline Test sample & $\mathrm{R}=0.1 \Delta \mathrm{K}=20 \mathrm{MPa} \sqrt{\mathrm{m}}$ & $\mathrm{R}=0.1 \Delta \mathrm{K}=40 \mathrm{MPa} \sqrt{\mathrm{m}}$ & $\mathrm{R}=0.7 \Delta \mathrm{K}=20 \mathrm{MPa} \sqrt{\mathrm{m}}$ \\
\hline $\begin{array}{c}\text { Proportion of crystallographic } \\
\text { propagation }\end{array}$ & $47 \%$ & $23 \%$ & $49 \%$ \\
\hline
\end{tabular}

\section{Discussions}

The results of this analysis confirm a decrease in crystallographic propagation after transition from the first to the second propagation regime, by a factor of two in the total length of segments related to crystallographic planes after transition. The influence of crystallography on the change between the two propagation regimes is therefore confirmed. The important crystallographic propagation in the first regime, similar for the two load ratio values investigated, induces important crack path deviations along crystallographic planes, and subsequently significant crack closure effects at $R=0.1$. These two shielding processes account for the higher performance of the lamellar microstructure, especially in the first propagation regime in comparison with bimodal microstructures [1]

However, above the transition, the reduction of "crystallographic" propagation is significant. $23 \%$ of propagation segments are related to basal or prismatic traces is the post-transition regime, showing that microstructure still have an influence after the transition.

\section{Conclusions and prospects}

The present work shows that fatigue crack propagation in lamellar microstructures of Ti-6Al-4V ELI alloy is strongly sensitive to crystallography. This sensitivity is very important in the first propagation regime that can be associated with a Stage I like propagation, with important propagation related to crystallographic planes. In the second propagation regime, the crack path is clearly less influenced by the crystallography.

Further work will consist in in-situ SEM tensile tests coupled with EBSD acquisition at specific $\triangle \mathrm{K}$ values (20 and $40 \mathrm{MPa} / \mathrm{m})$. This could allow to get better insight of the causes of this change in propagation mode. Tests will be performed on micro samples to observe the deformation process in relationship with local deformation mechanisms at the crack tip during loading. Samples will be machined in the crack tip region of the $\mathrm{CT}$ sample tested under constant $\Delta \mathrm{K}$ interrupted tests similar to those presented in this paper. 


\section{Acknowledgments}

This work has been performed in the frame of the IRT Saint-Exupéry-Metaltechnics project. The authors would like to thank all members of the Metaltechnics project and in particular Airbus Operations, Aubert and Duval, and Timet for their support.

\section{$\underline{\text { References }}$}

[1] Renon, V.; Henaff, G.; Larignon, C.; Perusin, S.; Villechaise, P. Identification of Relationships between Heat Treatment and Fatigue Crack Growth of a 3 Titanium Alloys. Metals 2019,9 , 512.

[2] G. R. Yoder, L. A. Cooley, et T. W. Crooker, "Quantitative analysis of microstructural effects on fatigue crack growth in widmanstätten Ti-6A1-4V and Ti-8Al-1Mo-1V ", Engineering Fracture Mechanics, vol. 11, no 4, p. 805-816, 1979.

[3] Irving, P.E.; Beevers, C.J. Microstructural influences on fatigue crack growth in Ti-6Al-4V, Mater. Sci. Eng. 1974, 14, 229-238.

[4] Yoder, G.R.; Cooley, L.A.; Crooker, T.W. Fatigue Crack Propagation Resistance of Beta-Annealed Ti-6Al-4V Alloys of differing interstitial oxygen contents. Metall. Trans. A 1978, 9A, 1413-1420. 